\title{
Article \\ Biological Characteristics of Verticillium dahliae MAT1-1 and MAT1-2 Strains
}

\author{
Lin Liu ${ }^{1,+}$, Ya-Duo Zhang ${ }^{2,+}$, Dan-Dan Zhang ${ }^{2}$, Yuan-Yuan Zhang ${ }^{1}{ }^{(D}$, Dan Wang ${ }^{2}$, Jian Song ${ }^{2}$, Jian Zhang ${ }^{1}$, \\ Ran Li ${ }^{2}$, Zhi-Qiang Kong ${ }^{2}$, Steven J. Klosterman ${ }^{3}$, Xiao-Feng Dai ${ }^{2}{ }^{\mathbb{D}}$, Krishna V. Subbarao ${ }^{4, *(D)}$, Jun Zhao ${ }^{1, *}$ \\ and Jie-Yin Chen ${ }^{2, * \mathbb{D}}$
}

1 College of Horticulture and Plant Protection, Inner Mongolia Agricultural University, Hohhot 010018, China; A_lin95@163.com (L.L.); y2015k@126.com (Y.-Y.Z.); zhj19890128@126.com (J.Z.)

2 Team of Crop Verticillium wilt, c/o State Key Laboratory for Biology of Plant Diseases and Insect Pests, Institute of Plant Protection, Chinese Academy of Agricultural Sciences, Beijing 100193, China; zyduo8@126.com (Y.-D.Z.); zhangdandan@caas.cn (D.-D.Z.); wangdan_star@163.com (D.W.); songiian_01@126.com (J.S.); liran01@caas.cn (R.L.); kongzhiqiang@caas.cn (Z.-Q.K.); daixiaofeng_caas@126.com (X.-F.D.)

3 United States Department of Agriculture, Agricultural Research Service, Crop Improvement and Protection Research Unit, Salinas, CA 93905, USA; Steve.Klosterman@usda.gov

4 Department of Plant Pathology, University of California, Davis, c/o U.S. Agricultural Research Station, Salinas, CA 93905, USA

* Correspondence: kvsubbarao@ucdavis.edu (K.V.S.); zhaojun@imau.edu.cn (J.Z.); chenjieyin@caas.cn (J.-Y.C.)

+ These authors contributed equally to this work.

Citation: Liu, L.; Zhang, Y.-D.; Zhang, D.-D.; Zhang, Y.-Y.; Wang, D.; Song, J.; Zhang, J.; Li, R.; Kong, Z.-Q.; Klosterman, S.J.; et al. Biological Characteristics of Verticillium dahliae MAT1-1 and MAT1-2 Strains. Int. J. Mol. Sci. 2021, 22, 7148. https:// doi.org/10.3390/ijms22137148

Academic Editor: Setsuko Komatsu

Received: 25 May 2021

Accepted: 29 June 2021

Published: 1 July 2021

Publisher's Note: MDPI stays neutral with regard to jurisdictional claims in published maps and institutional affiliations.

Copyright: (c) 2021 by the authors. Licensee MDPI, Basel, Switzerland. This article is an open access article distributed under the terms and conditions of the Creative Commons Attribution (CC BY) license (https:// creativecommons.org/licenses/by/ $4.0 /)$.
Abstract: Verticillium dahliae is a soil-borne plant pathogenic fungus that causes Verticillium wilt on hundreds of dicotyledonous plant species. V. dahliae is considered an asexually (clonal) reproducing fungus, although both mating type idiomorphs (MAT1-1 and MAT1-2) are present, and is heterothallic. Most of the available information on $V$. dahliae strains, including their biology, pathology, and genomics comes from studies on isolates with the MAT1-2 idiomorph, and thus little information is available on the MAT1-1 V. dahliae strains in the literature. We therefore evaluated the growth responses of MAT1-1 and MAT1-2 V. dahliae strains to various stimuli. Growth rates and melanin production in response to increased temperature, alkaline $\mathrm{pH}$, light, and $\mathrm{H}_{2} \mathrm{O}_{2}$ stress were higher in the MAT1-2 strains than in the MAT1-1 strains. In addition, the MAT1-2 strains showed an enhanced ability to degrade complex polysaccharides, especially starch, pectin, and cellulose. Furthermore, several MAT1-2 strains from both potato and sunflower showed increased virulence on their original hosts, relative to their MAT1-1 counterparts. Thus, compared to MAT1-1 strains, MAT1-2 strains derive their potentially greater fitness from an increased capacity to adapt to their environment and exhibit higher virulence. These competitive advantages might explain the current abundance of MAT1-2 strains relative to MAT1-1 strains in the agricultural and sylvicultural ecosystems, and this study provides the baseline information on the two mating idiomorphs to study sexual reproduction in $V$. dahliae under natural and laboratory conditions.

Keywords: Verticillium dahliae; MAT1-1 and MAT1-2 idiomorphs; Growth characteristics; Pathogenicity

\section{Introduction}

Sexual reproduction, a ubiquitous feature of the eukaryotic kingdom, can accelerate the adaptation to continuously changing ecological niches. It also allows the repair of random epigenetic or conventional genetic damage by recombination with homologous chromosomes [1,2]. However, approximately $20 \%$ of the fungal species reproduce only by asexual means, with no recognized sexual cycle [3,4]; and in Ascomycotina, nearly $40 \%$ of the taxa were deemed asexual [5]. Such strictly asexual organisms are thought to be less flexible than sexual organisms, relying solely on random mutations to adapt to changing environments; therefore, they are often considered evolutionary dead ends, 
mainly due to the absence of meiotic recombination, resulting in increased accumulation of deleterious mutations, an effect known as the Muller's ratchet [6-9]. Especially for plant pathogens that are engaged in an endless arms race with their hosts, attempting to ward off invading pathogens, relatively quick adaptations to coevolve with the host immune system are advantageous for evolutionary success [10]. However, accumulating evidence over the past few decades suggests that many of these supposedly asexual fungi might actually have the potential for sexual reproduction [11,12]. Examples include Candida albicans, Aspergillus flavus, Aspergillus fumigatus, and Aspergillus parasiticus [13-17], as well as the biotechnologically relevant species Penicillium chrysogenum, Penicillium roqueforti, and Trichoderma reesei [18-21].

In most fungi, the mating-type locus represents a relatively small region of the genome, less than a few thousand base pairs, encoding transcription factors that act as master regulators of sexual reproduction [22]. One idiomorph of the mating-type locus contains a critical gene that encodes an $\alpha$ domain (MAT1-1-1), while the other contains a gene that encodes a DNA-binding domain of the high-mobility group (HMG) (MAT1-2-1) [23]. In heterothallic species, sexual recombination occurs only between partners of opposite mating types; and in contrast, homothallic species normally contain both MAT loci, which can either be located at a single MAT locus or on different chromosomes [12,24]. However, the regulatory impact of MAT-encoded transcription factors and MAT gene expression alone does not necessarily indicate sexual potential. In asexual fungi, $M A T$ genes likely possess other important functions beyond mating. In the asexual Aspergillus oryzae, MAT1-1 and MAT1-2 specifically regulate over 1000 genes, including many with unknown functions [25]. In Penicillium chrysogenum, in addition to being involved in sexual development, MAT-controlled processes include asexual development, pallet morphology, polar hyphal growth, conidiospore germination, and secondary metabolite synthesis such as penicillin [26].

$V$. dahliae is a soil-borne, broad host-range plant pathogen that invades the xylem of susceptible plant species to cause vascular wilts [27,28]. Hundreds of dicotyledonous plants are hosts of $V$. dahliae, including many economically important crops such as lettuce, cotton, strawberries, and tomato $[27,29-31]$. V. dahliae is generally considered solely asexual (clonal), because the sexual cycle has never been documented either in nature or in the laboratory. The mating type idiomorph distribution in nature is skewed overwhelmingly toward MAT1-2, and extensive chromosomal rearrangements among different $V$. dahliae genomes could potentially interfere with meiosis. Moreover, the population structure of global $V$. dahliae strains is highly clonal [32-35]. This clonal structure is further complicated by abundant population subdivisions, including six main vegetative compatibility groups (VCGs) [36-38], races 1 (R1) and 2 (R2) that respond to host resistance genes in tomato and lettuce [39,40], a race 3 (R3) defined only in tomato [41], and two pathotypes, defoliating (D) and non-defoliating (ND) based on the presence or absence of defoliation caused by individual strains [42]. Some evidence supports a well-conserved ancestral or cryptic sexual reproduction in $V$. dahliae, including the two mating types in $V$. dahliae, and constitutively expressed sex-related genes [35]. Therefore, even though the evidence in the literature supports the clonal expansion of $V$. dahliae, the preservation of the machinery for sexual reproduction and the cryptic and ancestral sexual cycle in $V$. dahliae suggest that the potential for sexual reproduction exists in the fungus.

Most of the available information on $V$. dahliae strains, including the biology, pathology, genetics, and genomics, is derived from studies on strains carrying the MAT1-2 idiomorph [43-45], and information on the MAT1-1 idiomorph is scarce. The lack of information on the MAT1-1 idiomorph has limited our understanding and research into the sexual mode of reproduction in $V$. dahliae. In recent years, $V$. dahliae strains with the MAT1-1 idiomorph have been frequently recovered from potato and sunflower in the Inner Mongolia Autonomous Region of China, and the distribution of the two mating-type strains is close to 1:1, which will significantly increase the temporal and spatial proximity of two $V$. dahliae mating-type strains to potentially enable mating and increase the risk of sexual recombination. A more efficient genome evolution that results in a novel progeny 
may ensue. Therefore, a comparative analysis of the basic growth and pathogenic characteristics of strains carrying the two mating-type idiomorphs will provide important data for the genetic analysis of the two idiomorphs and to evaluate the possibility of sexual reproduction in $V$. dahliae.

\section{Results}

\subsection{Characteristics of V. dahliae MAT1-1 Strain P48 and MAT1-2 Strain P50}

To obtain comparative information on the MAT1-1 and MAT1-2 strains, V. dahliae strain P48 with MAT1-1 and P50 with MAT1-2 isolated from potato in Inner Mongolia, China, were selected. The upper sides of the P48 and P50 cultures displayed white dense mycelia on the PDA medium that progressively darkened on the undersurface of the cultures as the melanized microsclerotia were produced, at about 7 days after incubation (Figure 1A). During this interval, strain P50 produced more melanin than P48 (Figure 1A). The conidia from both strains were hyaline, elongated in clusters on phialides borne in whorls on branched aerial hyphae (Figure 1A), typical characteristics of $V$. dahliae [46].

A number of PCR primers have been designed to amplify loci or markers associated with race (D or ND phenotype) and mating type idiomorphs [35,46-48]. The PCR assays indicated that strain P48 had the MAT1-1 marker and P50 the MAT1-2 marker, confirming that P48 and P50 represented strains with MAT1-1 and MAT1-2 idiomorphs, respectively (Figure 1B). Strain P50 was also characterized as the ND pathotype and belonged to race 2, while strain P48 contained the race 2 marker, and it neither carried the D nor the ND marker, suggesting that both P48 and P50 were race 2 strains and that P50 likely is not able to cause the defoliating phenotype on hosts such as olive, cotton, and okra. The well-characterized, highly virulent defoliating strain Vd991 represents the D pathotype, belongs to race 2, and carries the MAT1-2 marker. It was used as a control in these experiments.

To detect the sequence conservation and variability of the two mating-type master regulatory genes in strains P48 and P50, the coding sequences of the MAT1-1-1 and MAT12-1 genes from these two strains were aligned with the corresponding genes from eight other sexually reproducing fungi, two of which were homothallic (Fusarium graminearum, Aspergillus nidulans) and six were heterothallic (Magnaporthe grisea, Aspergillus fumigatus, Neurospora crassa, Saccharomyces cerevisiae, Penicillium marneffei), along with those of the $V$. dahliae strain VdLs.17, which has been used as the reference genome in many studies [43]. The results showed that both P48 and P50 had the conserved $\alpha$ or HMG domains similar to other sexual fungi, and most amino acids in the $\alpha$ or HMG domains were also highly conserved (Figure 1C).

\subsection{Growth of MAT1-1 and MAT1-2 Strains under Different Culture Conditions}

The growth characteristics of the MAT1-1 strain P48 were compared with those of the MAT1-2 strain P50 in response to a range of temperatures, $\mathrm{pH}$ treatments, light/dark regimes, carbon sources, and stress conditions. Furthermore, the growth of five additional isolates of MAT1-1 (S2, S11, S109, P51, and P56) and MAT1-2 (S1, S12, S23, P52, and P90) strains from sunflower $(\mathrm{S})$ and potato $(\mathrm{P})$ was also determined to ensure that the results obtained with P48 and P50 were not unique to these strains. Detailed information on these strains is provided in Table S1. 

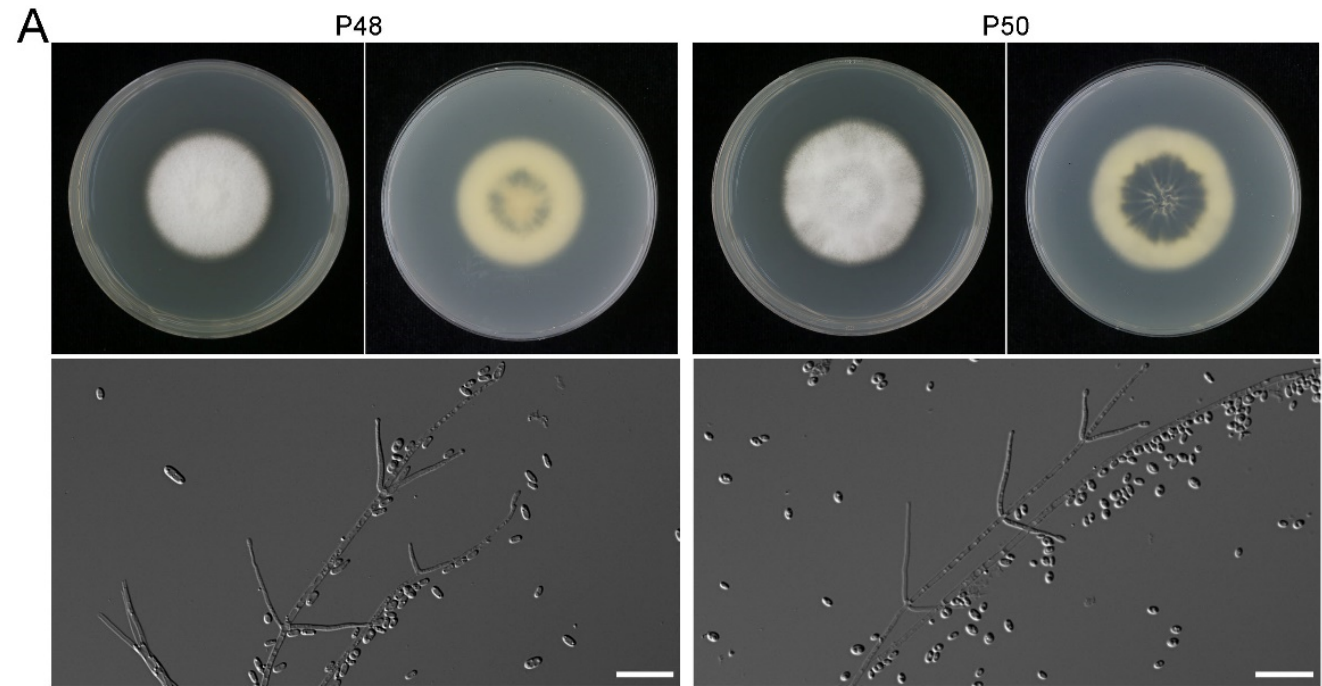

B
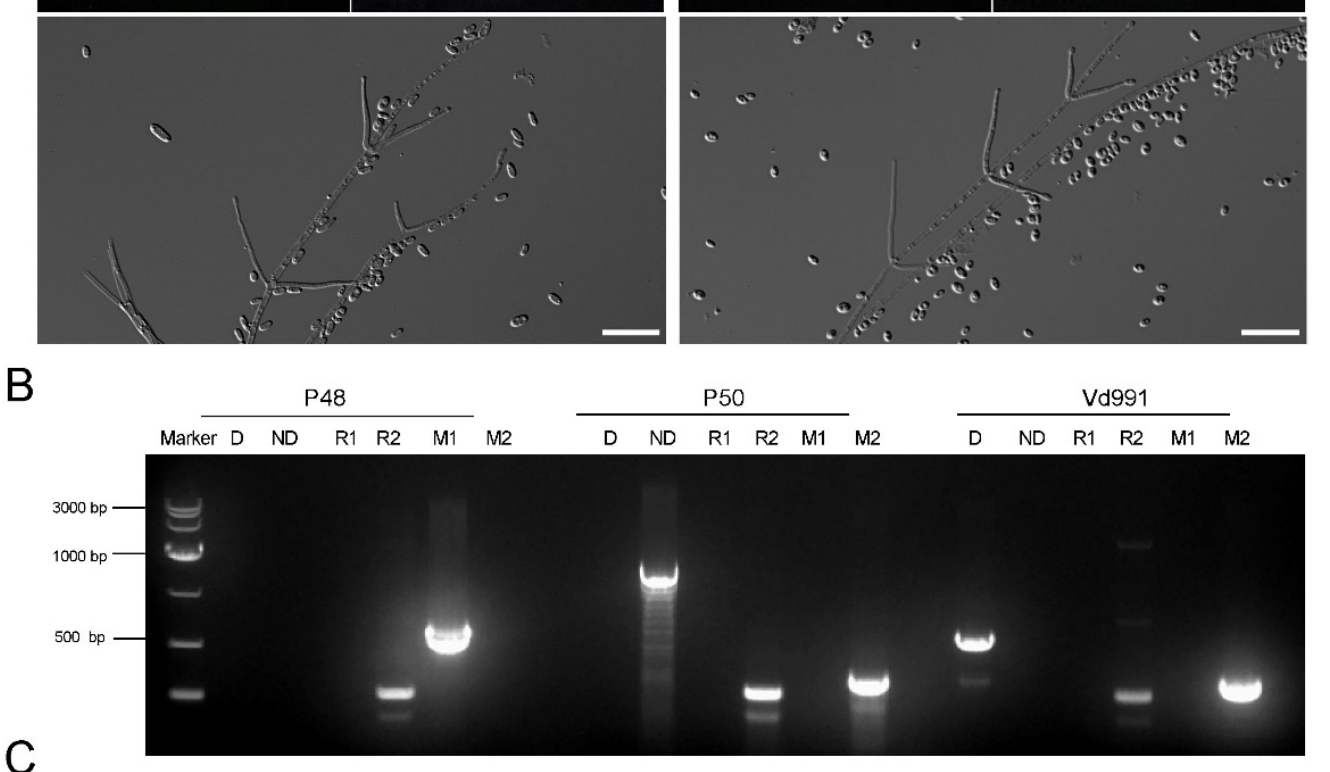

C

MAT1-1-1

$\begin{array}{lrl}\text { BAG83052.1 } & 5 \text { IDRYYIGPLETFIAGNRMLVSIDGRAVLVHKPVARQAQSVTSDQ----SRRTVKVRTSRPPNS YILYRKDHHKLIKAANP } \\ \text { V006706 } & 81 \text { IDRYYIGPLETFIA GNRMLVSIDGRAVLVHKPVAROAOSVT SDO--- SRRTVKVKISRP PNSYILYRKDHHKLIKAANP }\end{array}$ AAG42809.1 81 IDRYY IGP LETF IA GNR MLV S IDGRAVLVHKPVARQAQ SVT SDQ- - SRRTVKVKI SRP PNSY I LYRKDHHKLIKAANP

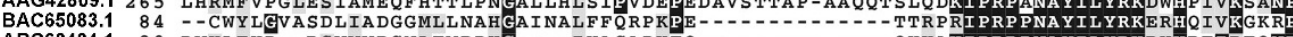
ABC6848.1 80 PVKLFKP-D -DVVVDGNLFWDPKG---I HASAPKEQ--

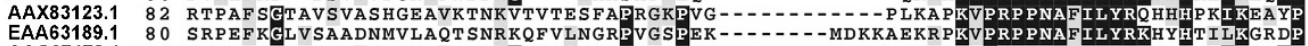

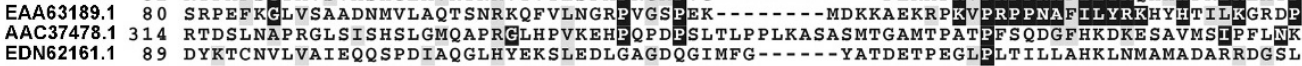
a domian

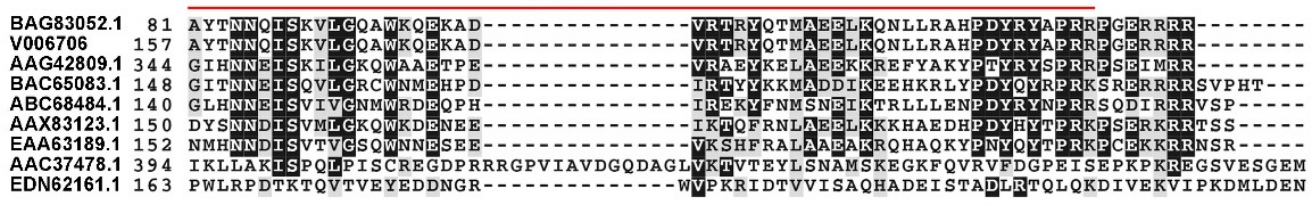
AAC37478.1 394 IKLLAKISPQUPISCREGDPRRRGPVIAVDGQDAGLVKTVTEYLSNAMSKE GKF QVRVFDGPEI SEPKP KREG SVE SGEM MAT1-2-1 HMG domain

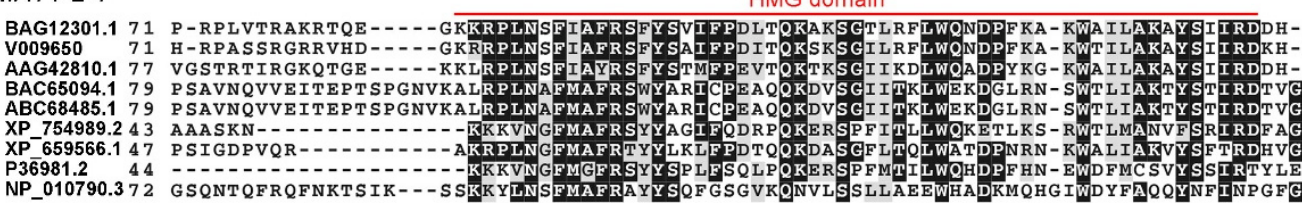

Figure 1. Morphology and genetic characterization of the Verticillium dahliae strains P48 and P50. (A) Colony phenotype and conidial morphology of $V$. dahliae stains P48 and P50 on PDA medium. (B) Results of molecular identification of Verticillium dahliae strains P48 and P50 using primers specific for MAT1-1 (M1)/MAT1-2 (M2), race 1 (R1)/race 2 (R2), and defoliating (D)/non-defoliating (ND) characteristics. (C) $\alpha$ and HMG domain comparison of sex-related transcriptional regulation factors MAT1-1-1 and MAT1-2-1 in P48 and P50 with other sexual fungi. BAG83052.1 and BAG12301.1: Verticillium dahliae VdLs.17; V006706 and V009650: Verticillium dahliae P48; AAG42809.1 and AAG42810.1: Fusarium graminearum; BAC65083.1 and BAC65094.1: Magnaporthe grisea; ABC68484.1 and ABC68485.1: Penicillium marneffei; AAX83123.1 and XP_754989.2: Aspergillus fumigatus; EAA63189.1 and XP_659566.1: Aspergillus nidulans; AAC37478.1 and P36981.2: Neurospora crassa; EDN62161.1 and NP_010790.3: Saccharomyces cerevisiae. 


\subsubsection{Temperature}

$V$. dahliae has an optimal temperature range of $22-27^{\circ} \mathrm{C}$, and limited growth occurs above $32{ }^{\circ} \mathrm{C}$ [49]. The MAT1-1 strain P48 produced a predominantly white mycelium, but the MAT1-2 strain P50 produced less mycelium, displayed faster colony growth, and accumulated higher amounts of melanin following incubation for 15 days at $25^{\circ} \mathrm{C}$ (Figure 2A).
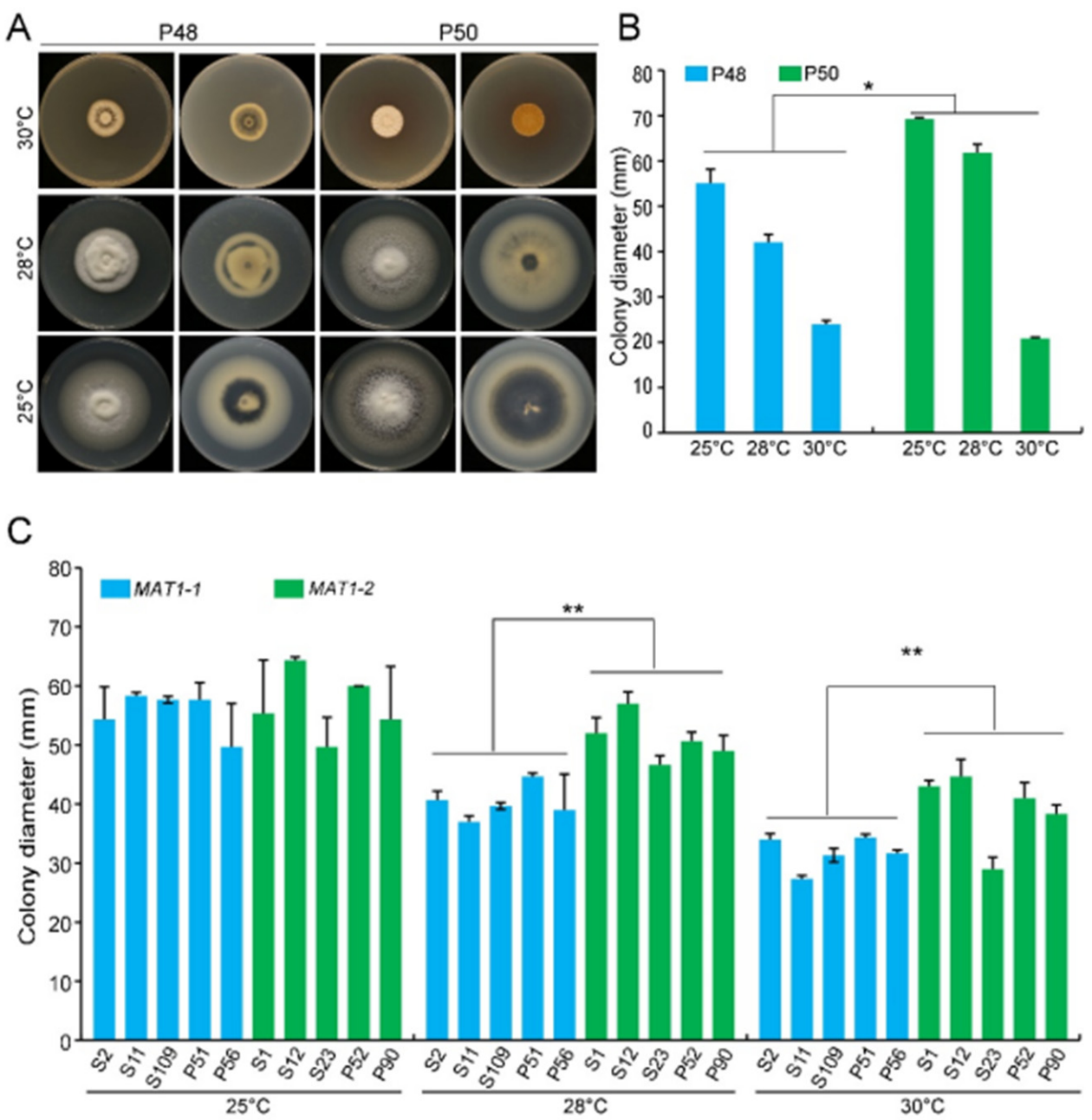

Figure 2. MAT1-1 and MAT1-2 strains of Verticillium dahliae grown under temperature stress conditions. (A) Growth phenotype of P48 and P50 on PDA medium at $25^{\circ} \mathrm{C}, 28^{\circ} \mathrm{C}$, and $30^{\circ} \mathrm{C}$ after culturing for 15 days. (B) Colony diameter of strains P48 and P50 on PDA medium at $25^{\circ} \mathrm{C}, 28^{\circ} \mathrm{C}$, and $30^{\circ} \mathrm{C}$ after culturing for 15 days. (C) Colony diameter of MAT1-1 and MAT1-2 strain collections on PDA medium at $25{ }^{\circ} \mathrm{C}, 28{ }^{\circ} \mathrm{C}$, and $30^{\circ} \mathrm{C}$ after culturing for 15 days. $\mathrm{P}$ and $\mathrm{S}$ indicate strains isolated from potato and sunflower, respectively. Asterisks * and ${ }^{* *}$ indicate significant differences; $p<0.05$ and $p<0.01$, respectively, according to an unpaired Student's $t$-test.

The growth rates of both $\mathrm{P} 50$ and $\mathrm{P} 48$ were significantly lower at $28^{\circ} \mathrm{C}$ and $30^{\circ} \mathrm{C}$ relative to $25^{\circ} \mathrm{C}$ (Figure 2A). However, even at $28^{\circ} \mathrm{C}$, the colony diameter of the MAT1-2 strain P50 was significantly larger than that of the MAT1-1 strain P48 (Figure 2A,B). At $30^{\circ} \mathrm{C}$, the growth of both strains was restricted and was not significantly different (Figure 2A,B). These results suggest that temperatures $<28^{\circ} \mathrm{C}$ had fewer influences on the MAT1-2 strain P50 than on the MAT1-1 strain P48, but once the temperature exceeded $30^{\circ} \mathrm{C}$, the growth of both strains was nearly arrested.

Additional MAT1-1 and MAT1-2 V. dahliae strains, under the optimum temperature $\left(25^{\circ} \mathrm{C}\right)$, showed no detectable differences in their growth rates for up to 15 days incubation, except that the MAT1-1 strains mainly developed white mycelia with less melanin 
accumulation than the MAT1-2 strains (Figure 2C and Figure S1). At $28{ }^{\circ} \mathrm{C}$ and $30{ }^{\circ} \mathrm{C}$, the diameters of the MAT1-2 strains were significantly higher than those of the MAT1-1 strains (Figure 2C and Figure S1). Higher temperatures therefore restrict growth and melanin production in both MAT1-1 and MAT1-2 strains, but these effects were more pronounced in the MAT1-1 strains than in the MAT1-2 strains.

\subsection{2. $\mathrm{pH}$}

Verticillium wilt of cotton normally occurs in near-neutral to alkaline soils at a $\mathrm{pH}$ in the range 6-9. At pH 5.5 or below, the growth, microsclerotia production, and survival of $V$. dahliae are generally inhibited [49]. Under laboratory conditions, the optimum $\mathrm{pH}$ for $V$. dahliae on the PDA medium was approximately 6.5. To determine the differences in the growth of the two idiomorphs, three PDA plates at $\mathrm{pH} 7.0,8.0$, and 9.0 each were incubated at $25^{\circ} \mathrm{C}$. Strain $\mathrm{P} 50$ produced more melanin under these $\mathrm{pH}$ values than at $\mathrm{pH}$ 6.5 (Figures $2 \mathrm{~A}$ and $3 \mathrm{~A}$ ). Melanin accumulation increased with increasing $\mathrm{pH}$, with the maximum melanin enrichment occurring at pH 9.0 (Figure 3A). However, the melanin production by the MAT1-1 strain P48 showed no obvious change with the pH (Figure 3A). Increasing $\mathrm{pH}$ did not alter the growth rates of either strain, but at each $\mathrm{pH}$ tested, P50 exhibited a higher colony growth than strain P48 (Figure 3A,B). Alkaline pH stimulated the accumulation of melanin by the two mating-type strains, but had no quantifiable influence on colony growth rates.
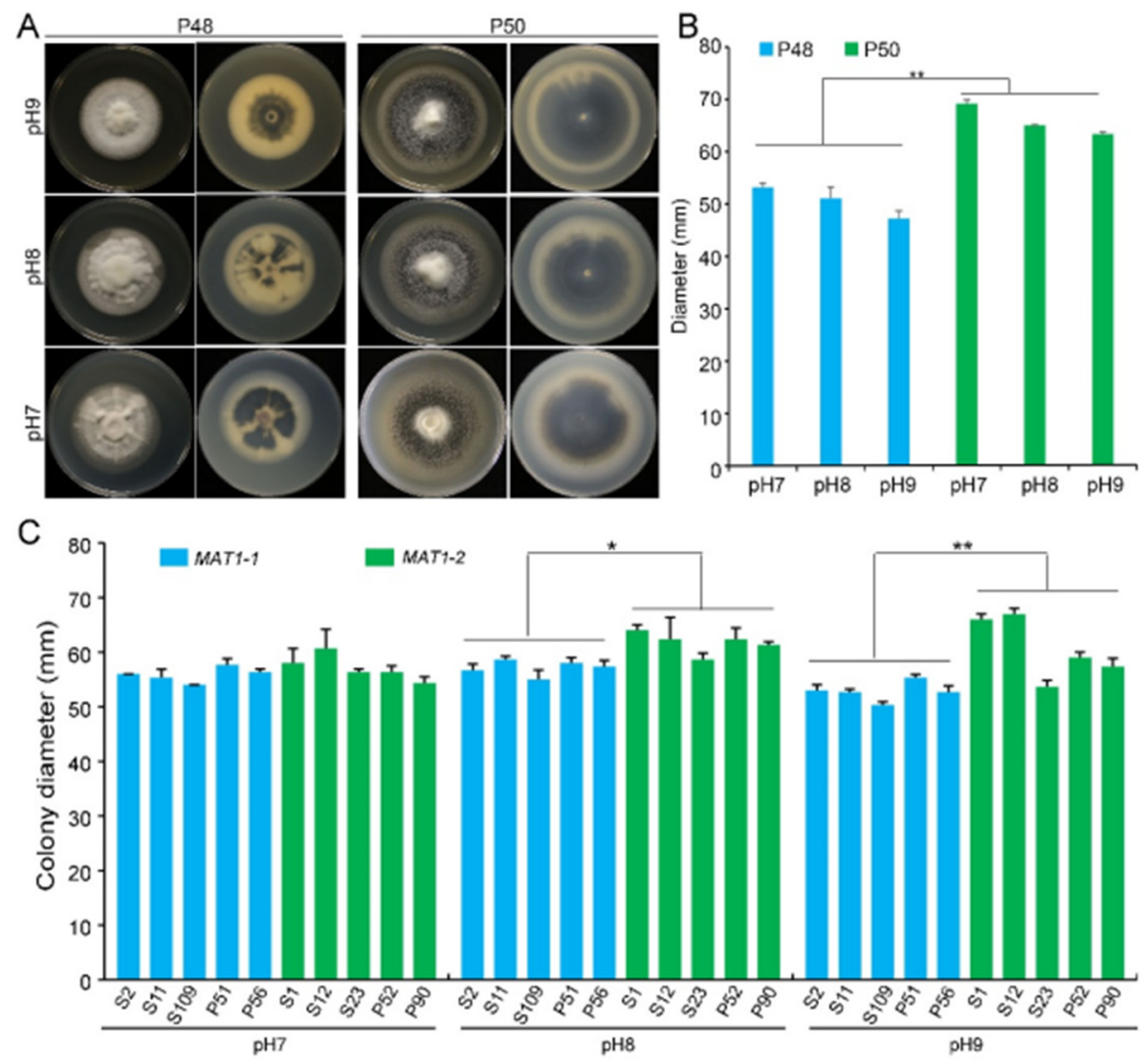

Figure 3. The influence of $\mathrm{pH}$ on the growth of MAT1-1 and MAT1-2 strains of Verticillium dahliae. (A) Growth phenotype of $\mathrm{P} 48$ and $\mathrm{P} 50$ at $\mathrm{pH} 7, \mathrm{pH}$ 8, and $\mathrm{pH} 9$ after culturing for 15 days. (B) Colony diameters of $\mathrm{P} 48$ and $\mathrm{P} 50$ at $\mathrm{pH} 7, \mathrm{pH} 8$, and $\mathrm{pH} 9$ after culturing for 15 days. (C) Colony diameter of MAT1-1 and MAT1-2 strain populations at $\mathrm{pH} \mathrm{7,} \mathrm{pH} 8$, and $\mathrm{pH} 9$ after culturing for 15 days. $\mathrm{P}$ and $S$ indicate strains isolated from potato and sunflower, respectively. Asterisks * and ${ }^{* *}$ indicate significant differences; $p<0.05$ and $p<0.01$, respectively, according to an unpaired Student's $t$-test. 
The growth rates of the five additional MAT1-1 strains were not altered by the $\mathrm{pH}$, but melanin accumulation was reduced at $\mathrm{pH} 8$ and 9, regardless of whether they were isolated from potato or sunflower. In contrast, MAT1-2 strains from potato and sunflower displayed higher growth rates at higher $\mathrm{pH}$, and melanin production was relatively unaffected compared to the MAT1-1 strains (Figure 3C and Figure S2). Overall, relative to the MAT1-1 strains, MAT1-2 strains not only grew faster but also accumulated more melanin under near-neutral and alkaline $\mathrm{pH}$.

\subsubsection{Light/Dark}

The growth of strains P48 and P50 was evaluated on a PDA medium at $25^{\circ} \mathrm{C}$ under dark and light conditions. Under the dark conditions examined, both the P48 and P50 strains produced melanin, although the growth rates and melanin accumulation in strain P50 were higher relative to those of P48 (Figure 4A). However, under the light conditions examined, neither P48 nor P50 produced visible melanin, with both forming only white mycelia (Figure 4A). The colony diameter of P48 was smaller under light conditions than under dark conditions, but the colony diameters of the P50 strain showed no obvious differences between light and dark conditions (Figure 4B). Under the light or dark conditions, the growth rates of P50 were higher than those of P48 (Figure 4B). These results suggested that light interfered with the melanin production in both strains and limited the rate of growth of the MAT1-1 strain P48 but did not influence the growth rate of the MAT1-2 strain P50.
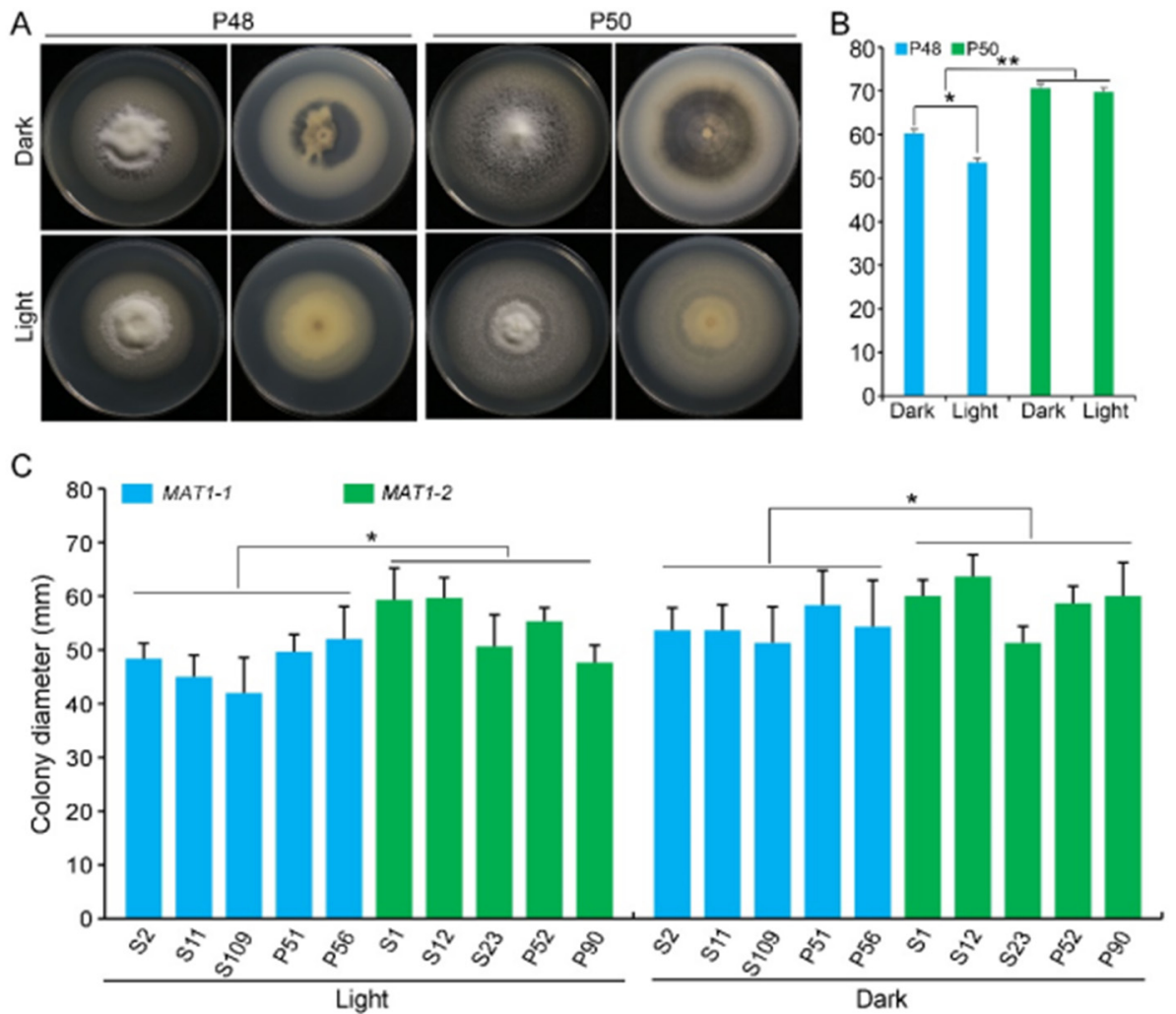

Figure 4. The effect of light and dark on MAT1-1 and MAT1-2 strains of Verticillium dahliae. (A) Growth phenotype of P48 and P50 under light and dark conditions after culturing for 15 days. (B) Colony diameters of P48 and P50 under light and dark conditions after culturing for 15 days. (C) Colony diameter of MAT1-1 and MAT1-2 strain populations under light and dark conditions after culturing for 15 days. $\mathrm{P}$ and $\mathrm{S}$ indicate strains isolated from potato and sunflower, respectively. Asterisks * and ${ }^{* *}$ indicate significant differences; $p<0.05$ and $p<0.01$, respectively, according to an unpaired Student's $t$-test. 
The influence of light was further examined on the growth of five additional strains from MAT1-1 and MAT1-2. Under the light conditions tested, there was no visible melanin production in the MAT1-1 strains, with the exception of S2 (Figure S3). Similarly, melanin accumulation in the MAT1-2 strains was also minimal under light, with only strains S23 and P52 producing small amounts of melanin (Figure S3). The growth rate of MAT1-2 strains whether under dark or light conditions was higher relative to that of the MAT1-1 strains; and MAT1-2 strains produced more melanin under the dark conditions than the MAT1-1 strains (Figure 4C and Figure S3). These results indicate that light restricted melanin production in both mating-types but had relatively less influence on the growth rate of MAT1-2 strains versus MAT1-1 strains.

\subsubsection{Carbon Source}

Verticillium species are capable of metabolizing a wide range of carbon sources, including glucose, mannose, rhamnose, sucrose, xylose, and cellobiose [50-52]. To examine the complex nutrient utilization capacity of the two MAT strains, their growth rates and phenotypes were evaluated on media containing different carbon sources, including the relatively simple disaccharide sucrose, but also complex polysaccharides like starch, pectin, and cellulose. The growth rates of the MAT1-2 strain P50 were higher compared to that of the MAT1-1 strain P48 on each of the media containing different carbon sources, and P50 also produced more melanin (Figure 5A,B). The higher growth of strain P50 suggested that the MAT1-2 strain has an increased capacity to degrade complex carbon sources, especially the complex polysaccharides pectin, cellulose, and starch. The MAT1-1 strain P48 produced mainly white mycelia on starch-, sucrose- and pectin-containing media with no apparent melanin production (Figure 5A). Melanin production was also significantly enriched in the MAT1-2 strain P50 on starch, sucrose, and pectin media, in addition to producing the typical white mycelia (Figure 5A). The growth of both mating type strains was limited on the medium containing cellulose as a carbon source, and there was little visible melanin production on this medium (Figure 5A). Both strains utilized pectin, but their ability to utilize cellulose was relatively weak compared with other complex polysaccharides examined.

Based on these results, three complex carbon sources were further evaluated on the larger panel of MAT1-1 and MAT1-2 strains. The MAT1-2 strains produced more melanin and less white mycelia than the MAT1-1 strains on the starch medium (Figure S4). When pectin served as the carbon source, both MAT1-1 and MAT1-2 strains produced melanin and mycelia (Figure 5C and Figure S4). When cellulose was the carbon source, similar to P48 and P50, the growth of other MAT1-1 and MAT1-2 strains was limited, with scant mycelia, small colony diameters, and little melanin accumulation (Figure S4). The colony diameters of all MAT1-2 strains were larger relative to those of the MAT1-1 strains on media containing the three selected carbon sources (Figure 5B and Figure S4). Since pectin and cellulose are some of the chief constituent complex polysaccharides in plants, MAT1-2 strains may have an enhanced capability, compared to MAT1-1 strains, to degrade plant cell wall components during infection and colonization processes.

\subsection{Stress Tolerance (Osmotic Stress, Oxidative Stress, Cell Wall Integrity Stress)}

To evaluate the stress tolerance of the two mating type strains, their growth on media that imposed osmotic stress (sorbitol-containing medium at three concentrations: 1, 1.5, and $2 \mathrm{~mol} / \mathrm{L})$, oxidative stress $\left(\mathrm{H}_{2} \mathrm{O}_{2}\right.$-containing medium at three concentrations: $0.9,1.2$, and $1.8 \mathrm{mmol} / \mathrm{L}$ ), and cell wall integrity stress (Congo red-containing medium at three concentrations: 100,200 , and $300 \mu \mathrm{g} / \mathrm{mL}$ ) was evaluated. 

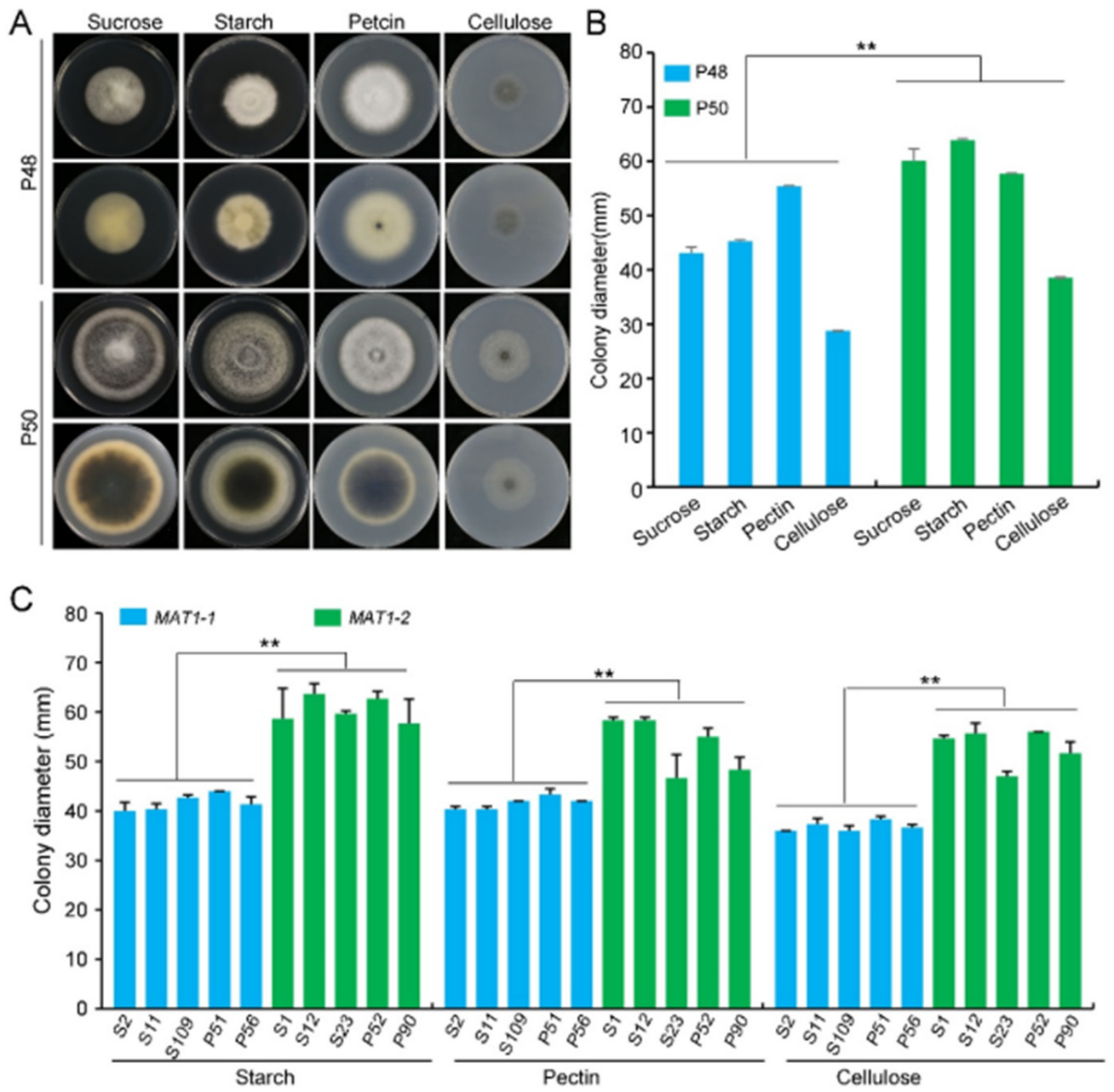

Figure 5. The influence of different carbon sources on the growth of MAT1-1 and MAT1-2 strains from Verticillium dahliae. (A) Growth of P48 and P50 on media types containing different carbon sources (sucrose, starch, pectin, cellulose). (B) Colony diameters of P48 and P50 on media types containing four carbon sources (sucrose, starch, pectin, cellulose) after culturing for 15 days. (C) Colony diameter of MAT1-1 and MAT1-2 populations on media types containing different carbon sources (sucrose, starch, pectin, cellulose) after culturing for 15 days. $\mathrm{P}$ and $\mathrm{S}$ indicate strains isolated from potato and sunflower, respectively. Asterisks ${ }^{* *}$ indicate significant differences; $p<0.01$, according to an unpaired Student's t-test.

Under osmotic stress, the growth rate of both P48 and P50 decreased as the sorbitol concentration increased, and there was no apparent melanin production under sorbitol stress. While there were no differences in the growth rates between the two strains under sorbitol concentrations of 1 and $1.5 \mathrm{~mol} / \mathrm{L}$, the growth rate of the P50 strain was higher relative to that of strain P48 at $2 \mathrm{~mol} / \mathrm{L}$ sorbitol (Figure S5A,B). Similarly, under cell wall integrity stress, the growth rates of both P48 and P50 decreased as the Congo red concentration increased (Figure S5C,D). Strain P50 produced more melanin at 100 and $200 \mu \mathrm{g} / \mathrm{L}$ Congo red than P48 (Figure S5C,D). Under the cell wall stress conditions tested, there were also no apparent differences in growth rate between the two strains (Figure S5D). The growth rates of both strains decreased as the oxidative stress from $\mathrm{H}_{2} \mathrm{O}_{2}$ concentration increased. However, there was almost no growth of strain P48 at the concentration of $1.8 \mathrm{mmol} / \mathrm{L} \mathrm{H}_{2} \mathrm{O}_{2}$ (Figure $6 \mathrm{~A}, \mathrm{~B}$ ). Unlike the other stress conditions examined, the growth rate of the MAT1-2 strain P50 was higher than that of the MAT1-1 strain P48 in response to $\mathrm{H}_{2} \mathrm{O}_{2}$, indicating that the MAT1-2 strain P50 had a greater resistance to oxidative stress than the MAT1-1 strain P48. 

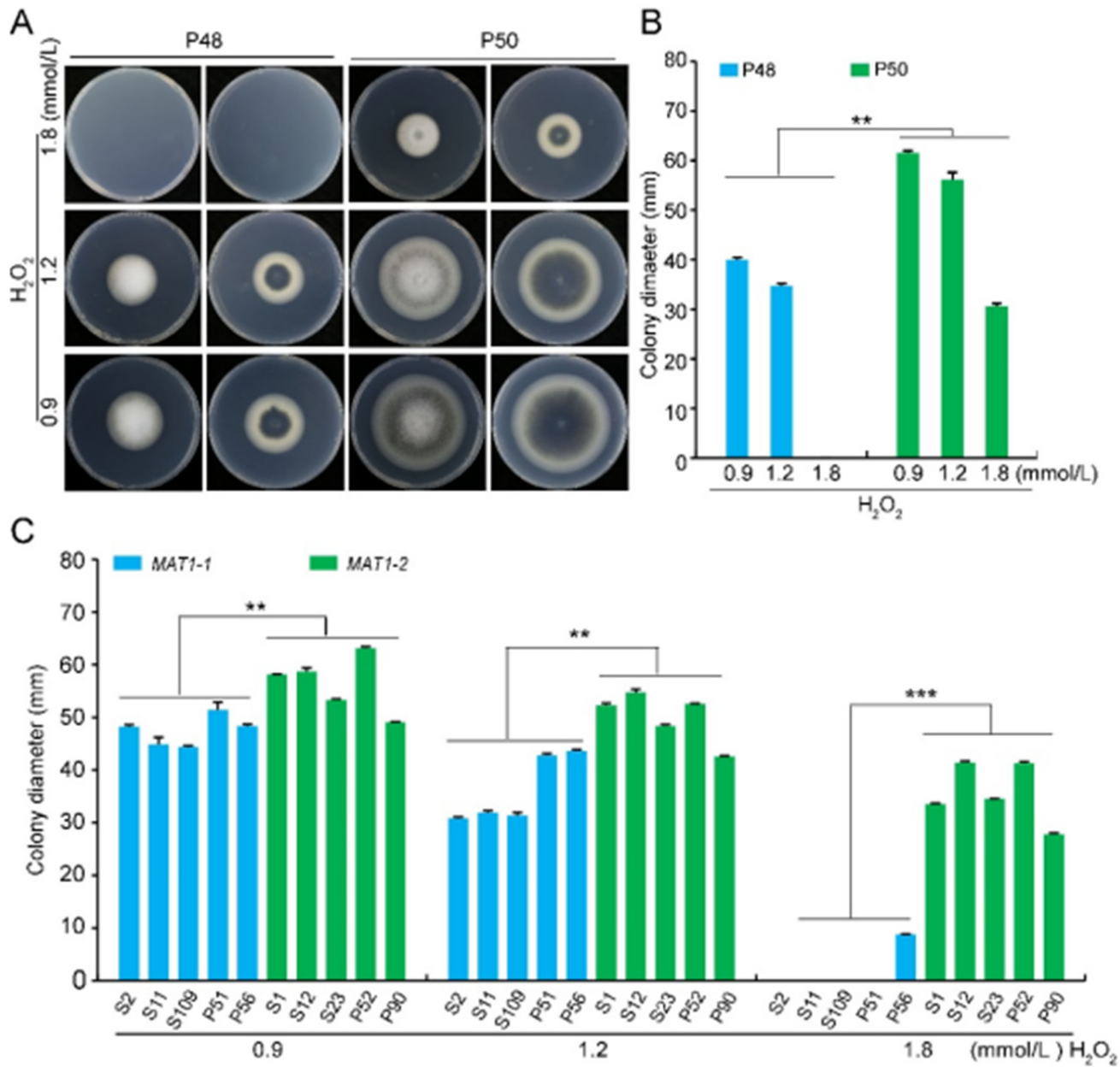

Figure 6. Growth of MAT1-1 and MAT1-2 strains of Verticillium dahliae in oxidative stress conditions. (A) Growth phenotype of $\mathrm{P} 48$ and $\mathrm{P} 50$ in response to serial concentrations of $\mathrm{H}_{2} \mathrm{O}_{2}(0.9,1.2$, $1.8 \mathrm{mmol} / \mathrm{L})$. (B) Colony diameters of strains P48 and P50 after culturing for 15 days with different concentrations of $\mathrm{H}_{2} \mathrm{O}_{2}(0.9,1.2,1.8 \mathrm{mmol} / \mathrm{L})$. (C) Colony diameters of MAT1-1 and MAT1-2 populations in response to serial concentrations of $\mathrm{H}_{2} \mathrm{O}_{2}(0.9,1.2,1.8 \mathrm{mmol} / \mathrm{L})$ at 15 days of growth. $\mathrm{P}$ and $\mathrm{S}$ indicate strains isolated from potato and sunflower, respectively. Asterisks ${ }^{* *}$ and ${ }^{* *}$ indicate significant differences; $p<0.01$ and $p<0.001$, respectively, according to an unpaired Student's $t$-test.

Colony diameters of the additional MAT1-1 strains evaluated were significantly smaller in size as the $\mathrm{H}_{2} \mathrm{O}_{2}$ concentration increased. At $1.8 \mathrm{mmol} / \mathrm{L}_{2} \mathrm{O}_{2}$ none of the MAT1-1 strains grew except P56, which produced very small colonies (Figure S6). The growth rates of the MAT1-2 strains were also slower as the $\mathrm{H}_{2} \mathrm{O}_{2}$ concentrations increased, the only difference being that the colony diameters were larger relative to those observed in the MAT1-1 strains

\subsection{Pathogenicity of MAT1-1 and MAT1-2 Strains on Their Original Hosts}

The virulence of the MAT1-1 and MAT1-2 strains was evaluated on potato or sunflower. Most of the MAT1-2 strains from potato were more virulent than the MAT1-1 strains on potato, except for strain P57 (Figure 7). However, the overall virulence of MAT1-2 and MAT1-1 strains from sunflower was not significantly different on sunflower (Figure 7). 

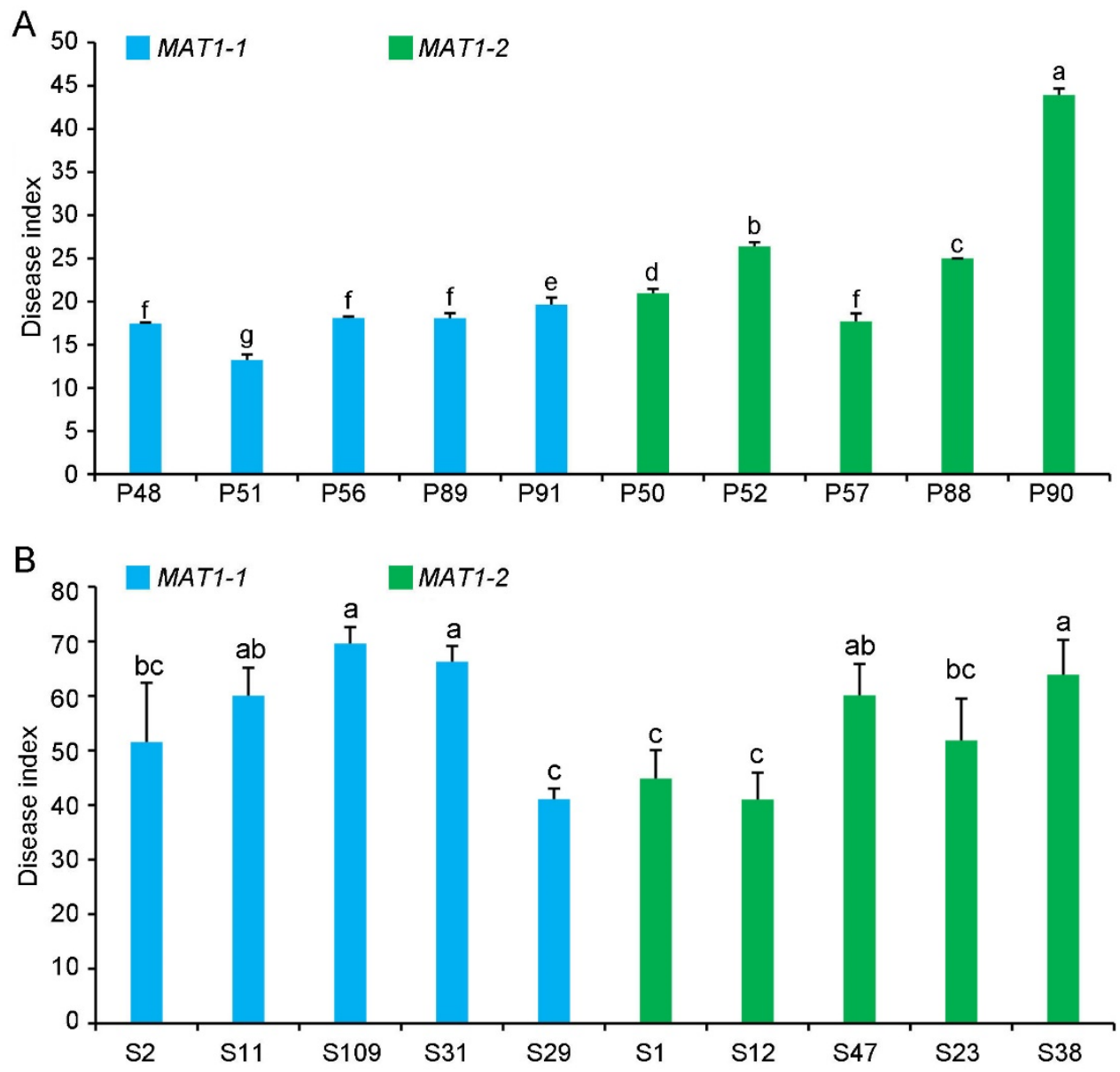

Figure 7. Pathogenicity of MAT1-1 and MAT1-2 strain populations of Verticillium dahliae on potato and sunflower. (A) Disease index of MAT1-1 and MAT1-2 strain populations isolated from potato (P) (MAT1-1 strains: P48, P51, P56, P89, P91; MAT1-2 strains: P50, P52, P57, P88, and P90) three weeks after inoculating potato (He 15). (B) Disease index of MAT1-1 and MAT1-2 strains isolated from sunflower (LD 5009) (S) (MAT1-1 strains: S2, S11, S109, S31, and S29; MAT1-2 strains: S1, S12, S47, S23, and S38) three weeks after the inoculation of sunflower. Columns with different letters represent a statistical significance of $p<0.05$ according to Duncan's new multiple range test.

\section{Discussion}

We compared the growth and the virulence of $V$. dahliae strains of opposite mating types derived from sunflower and potato. The MAT1-2 strains exhibited higher growth rates and melanin production under high temperatures, alkaline $\mathrm{pH}$, light, and oxidative stress (Figures 2-4 and 6). Additionally, MAT1-2 strains showed an enhanced ability to degrade complex polysaccharides, especially starch, pectin, and cellulose (Figure 5). Correspondingly, some MAT1-2 strains from potato also exhibited increased virulence relative to the MAT1-1 strains on potato. However, the difference in virulence between the two mating types were not apparent on sunflower (Figure 7). This research documents the overall higher adaptability of the MAT1-2 strains, that confers them greater fitness. This may help explain the major imbalance in the frequencies of the two mating idiomorphs in the agricultural and sylvicultural ecosystems, and provides information for future inquiries into the potential sexual cycle of $V$. dahliae under experimental conditions.

Temperature, as the single most important environmental factor, not only governs the germination of $V$. dahliae microsclerotia and disease development but also influences the geographic distribution of $V$. nonalfalfae and $V$. dahliae [49,53]. $V$. dahliae is mainly distributed in subtropical and temperate areas and has an optimal temperature in the range $22-27^{\circ} \mathrm{C}$, but limited growth occurs above $32{ }^{\circ} \mathrm{C}$. Devaux and Sackston [54] demonstrated that almost 
no microsclerotia formed at temperatures over $30^{\circ} \mathrm{C}$. Abundant microsclerotia formed between 18 and $30^{\circ} \mathrm{C}$ within $2-5$ days and after 30 days at $5{ }^{\circ} \mathrm{C}$, and no microsclerotia formed at $32{ }^{\circ} \mathrm{C}$ [55]. Colony growth and melanin production were altered as temperatures rose from $25^{\circ} \mathrm{C}$ to $30{ }^{\circ} \mathrm{C}$. At $30{ }^{\circ} \mathrm{C}$, especially, the colony growth rates decreased and there was almost no melanin accumulation (Figure 2A,B). Similarly, the larger panel of MAT1-1 and MAT1-2 strains showed no growth rate differences at $25^{\circ} \mathrm{C}$. The growth rate of the MAT1-2 strains was higher relative to those of the MAT1-1 strains as the temperature increased (Figure 2C), and also accumulated more melanin up to $30{ }^{\circ} \mathrm{C}$ (Figure S1). High temperature affected MAT1-2 strains less than MAT1-1 strains, indicating a stronger temperature tolerance of $V$. dahliae MAT1-2 strains. Melanin production in $V$. dahliae is also linked with protection against high temperature stress [56].

The maintenance of a constant $\mathrm{pH}$ was the single most important factor in maintaining optimal growth rates of $V$. dahliae, and in cotton production, the disease normally occurs in soils that are neutral to alkaline ( $\mathrm{pH} 6-9)$. Under acidic $\mathrm{pH}$ (5.5 or lower), the mycelial growth, microsclerotia production, and survival are all reduced [49]. Increases in the $\mathrm{pH}$ slightly reduced growth and melanin synthesis in the MAT1-1 strain P48 (Figure 3A). In contrast, growth was not influenced significantly with increasing $\mathrm{pH}$, but melanin production increased in the MAT1-2 strain P50 (Figure 3A). Overall, the optimum pH for MAT1-1 strains was approximately 7.0, but the MAT1-2 strains could grow and produce melanin under a broad $\mathrm{pH}$ range.

For a soil-borne and plant xylem-invading fungus like $V$. dahliae, a dark environment may represent an optimal condition for $V$. dahliae growth and proliferation. Some of the earliest research findings on melanin production in V. albo-atrum (reclassified as V. alfalfae and $V$. nonalfalfae by Inderbitzin et al. [46]) suggest that its resting mycelium formed sooner in total darkness than in daylight [57]. Caroselli et al. [58] also claimed that "green light" inhibited growth and that more microsclerotia were formed in "red light" and darkness. Conidial production by $V$. dahliae was greatly enhanced, but microsclerotia production was completely inhibited by blue light $[59,60]$. Some previous studies indicated that melanin occurs as electron-dense granules in the outer cell wall of microsclerotia, and melanin deposition is typically coupled with later stages of microsclerotial formation in $V$. dahliae [61,62]. Under light conditions, except for a few strains, there was almost no melanin production for all strains as compared to incubation in the dark (Figure 4A and Figure S3). Under light conditions, reduced melanin synthesis decreases the survival of $V$. dahliae, as these strains are highly sensitive to UV radiation [56]. This also corresponds to previous research showing that unmelanized conidia are more prone to rapid desiccation and damage by UV radiation $[58,63]$.

Verticillium spp. are capable of metabolizing a wide range of carbon sources, including glucose, fructose, arabinose, galactose, mannose, cellobiose, ribose, and xylose, as well as complex polysaccharides such as starch, pectin, and cellulose [52]. V. dahliae encodes a wide range of secreted pectinolytic and cellulolytic enzymes that may initiate infection and symptom development $[43,64]$. Thus, the capacity of $V$. dahliae to utilize different carbon sources is crucial for the infection of various host plants and the proliferation in host cells, including in the xylem, which consists of complex polysaccharides such as pectin, cellulose, and lignified cellulose [65]. The growth rates and melanin production of the MAT1-2 strain P50 were higher than those of the MAT1-1 strain P48 when sucrose, starch, cellulose, and pectin were used as carbon (Figure 5 and Figure S4). The cellulose utilization by both strains, however, was lower compared with the other three carbon sources. This was consistent with the growth of other $V$. dahliae strains on a cellulose-containing medium [66]. Although the growth rates of MAT1-2 strains were higher than in the MAT1-1 strains on media containing different polysaccharides, the melanin production in the MAT1-2 strains in general was not limited, unlike in strain P48 (Figure 5C and Figure S4). Nonetheless, the MAT1-2 strains generally had a higher polysaccharide utilization ability relative to the MAT1-1 strains. 
Congo red, sorbitol, and $\mathrm{H}_{2} \mathrm{O}_{2}$ have been widely used to detect fungal cell wall integrity and resistance to high concentrations of osmotic regulators and oxidative stress, respectively. Congo red interacts with various polysaccharides and exhibits a particularly high affinity with chitin and cellulose, which disturbs fungal cell wall morphogenesis [67-69]. The osmotic regulator sorbitol at high concentrations causes osmotic stress [70,71]. In response to pathogen infection, plants tend to produce more $\mathrm{H}_{2} \mathrm{O}_{2}$ to inhibit pathogen proliferation, and the reactive oxygen scavenging capacity has been viewed as an important evaluation index to assess pathogen infection ability and pathogenicity [56]. Under the Congo redand sorbitol-induced stress, the growth rates and melanin production of both MAT1-1 strain P48 and MAT1-2 strain P50 were impaired, except for the higher melanin production at relatively low Congo red concentrations (100 and $200 \mu \mathrm{g} / \mathrm{mL}$ ) by strain P50 (Figure S5). These results suggest that the sensitivities of the two strains to Congo red and sorbitol were similar. However, MAT1-1 and MAT1-2 strains responded differently to $\mathrm{H}_{2} \mathrm{O}_{2}$ stress, suggesting differing reactive oxygen scavenging abilities in the two mating-type populations.

In conclusion, under a higher temperature, alkaline $\mathrm{pH}$, response to light, and oxidative stress, the MAT1-2 strains exhibited higher growth rates and melanin production relative to those of the MAT1-1 strains. In addition, the MAT1-2 strains also had a higher complex polysaccharide degradation ability, suggesting that the MAT1-2 strains had wider environmental adaptability, that gave them greater fitness and survivability. These advantages may also confer the MAT1-2 strains higher virulence on select host plants. As demonstrated in this study, there was higher virulence of the MAT1-2 strains from potato when assayed on potato but such differences were not apparent with the two mating-type strains from sunflower when assayed for virulence on sunflower. Nonetheless, relative to the MAT1-1 strains, MAT1-2 strains exhibit an increased ability for environmental and potential host adaptation. The results of this research support the hypothesis that MAT1-2 strains are more adaptable, and therefore far more abundant in nature than the MAT1-1 strains. This research also provides the baseline information on the two mating idiomorphs to pursue studies of a potential sexual cycle in $V$. dahliae under different experimental conditions.

\section{Materials and Methods}

\subsection{Growth of V. dahliae Strains under Various Environmental Factors}

To determine the growth rates and colony morphology of $V$. dahliae MAT1-1 and MAT1-2 strains under different temperatures, $\mathrm{pH}$ changes, carbon sources, light and dark conditions, and conditions causing osmotic and cell wall stress, conidial suspensions of every strain were prepared at $5 \times 10^{6}$ conidia $/ \mathrm{mL}$, and $2 \mu \mathrm{L}$ was transferred to the center of Petri plates containing different media.

For temperature sensitivity assays, MAT1-1 and MAT1-2 strains were incubated on a potato dextrose agar (PDA) medium at $25^{\circ} \mathrm{C}, 28^{\circ} \mathrm{C}$, and $30^{\circ} \mathrm{C}$, respectively. Three plates for each temperature were incubated in each experiment, and the experiment was repeated three times. The $\mathrm{pH}$ of the PDA medium was adjusted to 7.0, 8.0, and 9.0 using $1 \mathrm{M} \mathrm{HCl}$ or $\mathrm{NaOH}$ to determine the $\mathrm{pH}$ sensitivity of all isolates at $25^{\circ} \mathrm{C}$. Growth under light and dark conditions was tested on a PDA medium, with each strain incubated at $25^{\circ} \mathrm{C}$. For the carbon source utilization assays, the strains were cultured at $25^{\circ} \mathrm{C}$ in basic $\mathrm{C}^{\prime}$ zapek medium agar plates that included sucrose $(30.0 \mathrm{~g} / \mathrm{L})$, starch $(17.0 \mathrm{~g} / \mathrm{L})$, pectin $(10.0 \mathrm{~g} / \mathrm{L})$, or cellulose $(10.0 \mathrm{~g} / \mathrm{L})$ as the carbon source, respectively [72]. Again, three plates at each $\mathrm{pH}$ and isolate were incubated per experiment, and the experiment was repeated three times.

PDA plates containing $0.9,1.2$, and $1.8 \mathrm{mmol} / \mathrm{L} 30 \% \mathrm{H}_{2} \mathrm{O}_{2}$ were used to test all MAT11 and MAT1-2 isolates to oxidative stress. For osmotic stress experiments, strains P48 and P50 were inoculated and cultured on a complete medium $(\mathrm{CM}$, Yeast extract $6.0 \mathrm{~g} / \mathrm{L}$, Casein acids hydrolysate $6.0 \mathrm{~g} / \mathrm{L}$, sucrose $10.0 \mathrm{~g} / \mathrm{L}$ ) at $25^{\circ} \mathrm{C}$ supplemented with $1,1.5$, and $2 \mathrm{~mol} / \mathrm{L}$ sorbitol, respectively. For cell wall stress assays, strains P48 and P50 were 
incubated on CM plates that were supplemented with 100, 200, and $300 \mu \mathrm{g} / \mathrm{mL}$ Congo red (Sigma-Aldrich) at $25^{\circ} \mathrm{C}$.

The growth of all strains under different culture conditions were evaluated after 15 days of incubation by measuring the colony diameters. Each strain was cultured on five plates for each of the treatments, and the experiments were repeated two times. Unpaired Student's $t$-tests were performed to determine the statistical significance among strains at $p \leq 0.05, p \leq 0.01$, or $p \leq 0.005$.

\subsection{DNA Extraction and Genotype Identification Assays of $V$. dahliae Strains}

High conidial suspensions $\left(1 \times 10^{8}\right.$ conidia/mL) of $V$. dahliae strains P48, P50, and Vd991 were placed on a PDA medium and incubated at $25^{\circ} \mathrm{C}$, and the mycelium was collected after 7 days. The total genomic DNA was extracted for the identification of mating types, races, and D and ND types. Genomic DNA of each isolate was extracted using a FastPure Plant DNA Isolation Mini Kit (Vazyme, Nanjing, China) following the manufacturer's instructions and was stored at $-20^{\circ} \mathrm{C}$ for polymerase chain reaction (PCR) assays.

For the genotype identification assays, D/ND, race1/2, and MAT1-1/MAT1-2 were determined by PCR with previously developed primers [35,73,74] (Table S2). All PCR assays in this study were performed in $20 \mu \mathrm{L}$ reaction volumes using $2 \times$ Taq Mester Mix (Dye Plus) P112-AA (Vazyme, Nan Jing, China). PCR was performed under the following conditions: an initial $94{ }^{\circ} \mathrm{C}$ denaturation step for $10 \mathrm{~min}$, followed by 30 cycles at $94{ }^{\circ} \mathrm{C}$ for $30 \mathrm{~s}$, annealing at $58^{\circ} \mathrm{C}$ for $30 \mathrm{~s}$, extension at $72{ }^{\circ} \mathrm{C}$ for $1 \mathrm{~min}$, and a final extension of $10 \mathrm{~min}$ at $72{ }^{\circ} \mathrm{C}$. The PCR products were detected by $1 \%$ agarose (Sigma-Aldrich, St. Louis, MO, USA) gel dyed with GelStain (TransGen, Beijing, China) and electrophoresis for 20 min at $120 \mathrm{~V}$ in $1 \times$ TAE buffer. Then the image was obtained with the Bio-Rad's ChemiDoc XRS system.

\subsection{Gene Cloning and Bioinformatics Analysis}

The mycelia of strains P48 and P50 were collected 7 days after culture at $25^{\circ} \mathrm{C}$ on a PDA medium. The total RNA of P48 or P50 was extracted using the Total RNA Miniprep Kit (Axygen, MA, USA), and first-strand cDNA was synthesized using the RevertAid First Strand cDNA Synthesis Kit (Thermo Scientific, Waltham, MA, USA). The targeted genes (MAT1-1-1 and MAT1-2-1) were amplified from the prepared cDNA using the primers listed in Table S2.

Protein sequence alignments deduced from MAT1-1-1 and MAT1-2-1 of strains P48 and P50, respectively, were performed with other published fungal mating-type protein sequences (Verticillium dahliae VdLs.17: BAG83052.1 and BAG12301.1, Fusarium graminearum: AAG42809.1 and AAG42810.1, Magnaporthe grisea: BAC65083.1 and BAC65094.1, Penicillium marneffei: ABC68484.1 and ABC68485.1, Aspergillus fumigatus: AAX83123.1 and XP_754989.2, Aspergillus nidulans: EAA63189.1 and XP_659566.1, Neurospora crassa: AAC37478.1 and P36981.2, and Saccharomyces cerevisiae: EDN62161.1 and NP_010790.3). A sequence alignment analysis and domain prediction were conducted using Clustal X2 (http://www.clustal.org/clustal2/ (accessed on 24 August 2020)) and BoxShade (https:/ / embnet.vital-it.ch/software/BOX_form.html (accessed on 24 August 2020)).

\subsection{Virulence of MAT1-1 and MAT1-2 Strains}

Ten MAT1-1 (P48, P51, P56, P89, P91, S2, S11, S109, S31, S29) and MAT1-2 (P50, P52, P57, P88, P90, S1, S12, S23, S47, S38) V. dahliae strains were selected for virulence assays. Assays were performed as described previously by Xiao et al. [75], with some modifications. All strains were cultured on a PDA medium for 7 days, transferred to a wheat bran medium, and incubated at $25^{\circ} \mathrm{C}$ for 15 days until the medium was covered with mycelium. Conidia were harvested with distilled water and filtered with Miracloth (Solarbio, Beijing, China), and a $1 \times 10^{7}$ conidia/mL inoculum suspension was used in the virulence assays. 
Sunflower (cv. He 15) seeds were sown with 5 seeds in each pot, and potatoes (cv. LD 5009) were planted with two tubers in each pot, with each tuber containing at least $2-3$ bud eyes. The pots were incubated at $28^{\circ} \mathrm{C}$ in the greenhouse with alternating $16 \mathrm{~h} / 8 \mathrm{~h}$ light- dark periods. Four-week-old sunflower and potato seedlings were inoculated by flooding $200 \mathrm{~mL}$ conidial suspension as described by Alkher et al. and Xiao et al. [75,76]. The plants were examined for symptoms weekly, and the quantification of disease parameters was performed at three weeks post-inoculation following the methods of Xiao et al. and Alkher et al. [75,76]. Five pots of sunflowers and ten pots of potatoes were used for each $V$. dahliae strain, and the experiment was repeated three times. The quantification of disease parameters was done as follows: Potato Verticillium wilt was rated on a 0 to 5 scale, where $0=$ healthy plants with no foliar chlorosis and necrosis; $1=$ visible leaf chlorosis with less than $1 \%$ necrosis; 2 = up to $40 \%$ chlorosis and $1-20 \%$ necrosis; $3=$ up to $65 \%$ chlorosis and $21-35 \%$ necrosis; $4=100 \%$ chlorosis, $36-70 \%$ necrosis; and $5=100 \%$ chlorosis, $71-100 \%$ necrosis.

Verticillium wilt on sunflower was rated on a $0-4$ scale, where $0=$ healthy plants with no foliar chlorosis; $1=25 \%$ foliar chlorosis and stunting; $2=26-50 \%$ foliar chlorosis and stunting; $3=51-75 \%$ foliar chlorosis and stunting; $4=$ more than $75 \%$ of the leaves with severe chlorosis and stunting, along with plants' death.

The disease indices for the potato and sunflower virulence assays were calculated according to the formula: $=100 \times \sum$ (number of diseased leaves in each scale rating $\times$ representative value in each rating)/(total number of leaves examined $\times$ maximum rating value).

Supplementary Materials: The following are available online at https://www.mdpi.com/article/10 .3390 /ijms22137148/s1, Figure S1: Growth phenotype of MAT1-1 and MAT1-2 strain populations at $25^{\circ} \mathrm{C}, 28^{\circ} \mathrm{C}$, and $30^{\circ} \mathrm{C}$ on PDA medium after culturing for 15 days.Figure S2: Growth phenotype of MAT1-1 and MAT1-2 strain populations on PDA after culturing for 15 days in medium adjusted to $\mathrm{pH}$ 7, $\mathrm{pH} 8$, and $\mathrm{pH}$ 9. Figure S3: Growth phenotype of MAT1-1 and MAT1-2 strain populations under light and dark conditions for 15 days. Figure S4: Growth phenotype of MAT1-1 and MAT1-2 strain populations after culturing for 15 days in media types containing different carbon sources. Figure S5: Growth of strains P48 and P50 under two stress tolerance conditions. Figure S6: Growth of MAT1-1 and MAT1-2 strain populations under conditions of oxidative stress. Table S1: Information on all MAT1-1 and MAT1-2 strain populations. Table S2: Primers information used in this study

Author Contributions: J.-Y.C., K.V.S., J.Z. (Jun Zhao) conceived this research. L.L., Y.-D.Z. and D.-D.Z. designed and directed the study. Y.-Y.Z., D.W., J.S., J.Z. (Jian Zhang), R.L. and Z.-Q.K. assisted with specific experiments. J.-Y.C. and D.-D.Z. prepared the manuscript, which was reviewed and edited by S.J.K., K.V.S., J.Z. (Jun Zhao) and X.-F.D. L.L. and Y.-D.Z. contributed equally. None of the authors have conflicts of interest with this manuscript. All authors have read and agreed to the published version of the manuscript.

Funding: This work was supported by the National Key Research and Development Program of China (2018YFE0112500; 2017YFD0201900), the Elite Youth Program CAAS to J.Y.C., the National Natural Science Foundation of China (31972228, 31970142, 31870138, 31772245, and 31671986), the Agricultural Science and Technology Innovation Program grant to X.F.D., and the Fundamental Research Funds for Central Nonprofit Scientific Institution (Y2018PT70).

Institutional Review Board Statement: Not applicable.

Informed Consent Statement: Not applicable.

Acknowledgments: We thank Research Assistant Xiaowei Liu for her supports in the process of experiment.

Conflicts of Interest: Authors declare no conflict of interest.

\section{References}

1. Normark, B.B.; Judson, O.P.; Moran, N.A. Genomic signatures of ancient asexual lineages. Biol. J. Linn. Soc. 2003, 79, 69-84. [CrossRef]

2. Gorelick, R.; Carpinone, J. Origin and maintenance of sex: The evolutionary joys of self sex. Biol. J. Linn. Soc. 2009, 98, 707-728. [CrossRef] 
3. Hawksworth, D.L.; Kirk, P.M.; Sutton, B.C.; Pegler, D.N. Ainsworth E Bisby's Dictionary of the Fungi, 8th ed.; CABI: Wallingford, UK, 1995.

4. Taylor, J.W.; Geiser, D.M.; Burt, A.; Koufopanou, V. The evolutionary biology and population genetics underlying fungal strain typing. Clin. Microbiol. Rev. 1999, 12, 126-146. [CrossRef] [PubMed]

5. Reynolds, D.R. The Fungal Holomorph: An Overview. In The Fungal Holomorph: Mitotic, Meiotic and Pleomorphic Speciation in Fungal Systematics; Reynolds, D.R., Taylor, J.W., Eds.; CABI: Wallingford, UK, 1993; pp. 15-25.

6. Felsenstein, J. The evolutionary advantage of recombination. Genetics 1974, 78, 737-756. [CrossRef] [PubMed]

7. Burt, A. Perspective: Sex, recombination, and the efficacy of selection-Was Weismann right? Evolution 2000, 54, 337-351. [PubMed]

8. McDonald, B.A.; Linde, C. Pathogen population genetics, evolutionary potential, and durable resistance. Annu. Rev. Phytopathol. 2002, 40, 349-379. [CrossRef]

9. Heitman, J. Sexual reproduction and the evolution of microbial pathogens. Curr. Biol. 2006, 16, 711-725. [CrossRef]

10. Raffaele, S.; Kamoun, S. Genome evolution in filamentous plant pathogens: Why bigger can be better. Nat. Rev. Microbiol. 2012, 10, 417-430. [CrossRef]

11. Kück, U.; Pöggeler, S. Cryptic sex in fungi. Fungal Biol. Rev. 2009, 23, 86-90. [CrossRef]

12. Dyer, P.S.; Inderbitzin, P.; Debuchy, R. Mating-Type Structure, Function, Regulation and Evolution in the Pezizomycotina. In Growth, Differentiation and Sexuality, The Mycota I, 3rd ed.; Wendland, J., Ed.; Springer: Cham, Switzerland, 2016 ; pp. 351-385.

13. Hull, C.M.; Raisner, R.M.; Johnson, A.D. Evidence for mating of the "asexual" yeast Candida albicans in a mammalian host. Science 2000, 289, 307-310. [CrossRef]

14. Magee, B.B.; Magee, P.T. Induction of mating in Candida albicans by construction of MTLa and MTL $\alpha$ strains. Science 2000, 289, 310-313. [CrossRef]

15. Horn, B.W.; Moore, G.G.; Carbone, I. Sexual reproduction in Aspergillus flavus. Mycologia 2009, 101, 423-429. [CrossRef]

16. Horn, B.W.; Ramirez-Prado, J.H.; Carbone, I. Sexual reproduction and recombination in the aflatoxin-producing fungus Aspergillus parasiticus. Fungal Genet. Biol. 2009, 46, 169-175. [CrossRef] [PubMed]

17. O'Gorman, C.M.; Fuller, H.; Dyer, P.S. Discovery of a sexual cycle in th opportunistic fungal pathogen Aspergillus fumigatus. Nature 2009, 457, 471-474. [CrossRef]

18. Seidl, V.; Seibel, C.; Kubicek, C.P.; Schmoll, M. Sexual development in the industrial workhorse Trichoderma reesei. Proc. Natl. Acad. Sci. USA 2009, 106, 13909-13914. [CrossRef]

19. Böhm, J.; Hoff, B.; O'Gorman, C.M.; Wolfers, S.; Klix, V.; Binger, D.; Zadra, I.; Kürnsteiner, H.; Pöggeler, S.; Dyer, P.S.; et al. Sexual reproduction and mating-type-mediated strain development in the penicillin-producing fungus Penicillium chrysogenum. Proc. Natl. Acad. Sci. USA 2013, 110, 1476-1481. [CrossRef] [PubMed]

20. Swilaiman, S.S. Sexual Potential and Population Biology of Fungal Aspergillus and Penicillium Species. Ph.D. Thesis, University of Nottingham, Nottingham, UK, 2013.

21. Ropars, J.; López-Villavicencio, M.; Dupont, J.; Snirc, A.; Gillot, G.; Coton, M.; Jany, J.L.; Coton, E.; Giraud, T. Induction of sexual reproduction and genetic diversity in the cheese fungus Penicillium roqueforti. Evol. Appl. 2014, 7, 433-441. [CrossRef]

22. Dyer, P.S.; Kück, U. Sex and the Imperfect Fungi. Microbiol. Spectr. 2017, 5, 43-2017. [CrossRef] [PubMed]

23. Debuchy, R.; Turgeon, B.G. Mating-Type Structure, Evolution, and Function in Euascomycetes. In The Mycota Volume I: Growth, Differentiation and Sexuality; Springer: Berlin, Germany, 2006; pp. 293-323.

24. Ni, M.; Feretzaki, M.; Sun, S.; Wang, X.; Heitman, J. Sex in fungi. Annu. Rev. Genet. 2011, 45, 405-430. [CrossRef]

25. Wada, R.; Maruyama, J.; Yamaguchi, H.; Yamamoto, N.; Wagu, Y.; Paoletti, M.; Archer, D.B.; Dyer, P.S.; Kitamoto, K. Presence and functionality of mating type genes in the supposedly asexual filamentous fungus Aspergillus oryzae. Appl. Environ. Microbiol. 2012, 78, 2819-2829. [CrossRef]

26. Böhm, J. Mating-Type Genes and the Sexual Cycle of the Penicillin Producer Penicillium chrysogenum. Ph.D. Thesis, RuhrUniversity Bochum, Bochum, Germany, 2014.

27. Fradin, E.F.; Thomma, B.P.H.J. Physiology and molecular aspects of Verticillium wilt diseases caused by V. dahliae and V. albo-atrum. Mol. Plant Pathol. 2006, 7, 71-86. [CrossRef]

28. Klosterman, S.J.; Atallah, Z.K.; Valled, G.E.; Subbarao, K.V. Diversity, pathogenicity, and management of Verticillium species. Annu. Rev. Phytopathol. 2009, 47, 39-62. [CrossRef]

29. Bolek, Y.; El-Zik, K.M.; Papper, A.E.; Bell, A.A.; Magill, C.W.; Thaxton, P.M.; Reddy, O.U.K. Mapping of Verticillium wilt resistance genes in cotton. Plant Sci. 2005, 168, 1581-1590. [CrossRef]

30. Inderbitzin, P.; Subbarao, K.V. Verticillium systematics and evolution: How confusion impedes Verticillium wilt management and how to resolve it. Phytopathology 2014, 104, 564-574. [CrossRef] [PubMed]

31. Atallah, Z.K.; Hayes, R.J.; Subbarao, K.V. Fifteen years of Verticillium wilt of lettuce in America's Salad Bowl: A tale of immigration, subjugation and abatement. Plant Dis. 2011, 95, 784-792. [CrossRef] [PubMed]

32. Usami, T.; Itoh, M.; Amemiya, Y. Mating type gene MAT1-2-1 is common among Japanese isolates of Verticillium dahliae. Physiol. Mol. Plant Pathol. 2008, 73, 133-137. [CrossRef]

33. Atallah, Z.K.; Maruthachalam, K.; du Toit, L.; Koike, S.T.; Davis, R.M.; Klosterman, S.J.; Hayes, R.J.; Subbarao, K.V. Population analyses of the vascular plant pathogen Verticillium dahliae detect recombination and transcontinental gene flow. Fungal Genet. Biol. 2010, 47, 416-422. [CrossRef] [PubMed] 
34. Inderbitzin, P.; Davis, R.M.; Bostock, R.M.; Subbarao, K.V.; Litvintseva, A. The ascomycete Verticillium longisporum is a hybrid and a plant pathogen with an expanded host range. PLoS ONE 2011, 6, e18260. [CrossRef] [PubMed]

35. Short, D.P.G.; Gurung, S.; Hu, X.; Inderbitzin, P.; Subbarao, K.V. Maintenance of sex-related genes and the co-occurrence of both mating types in Verticillium dahliae. PLoS ONE 2014, 9, e112145. [CrossRef]

36. Bhat, R.G.; Smith, R.G.; Koike, S.T.; Wu, B.M.; Subbarao, K.V. Characterization of Verticillium dahliae isolates and wilt epidemics in pepper. Plant Dis. 2003, 87, 789-797. [CrossRef]

37. Joaquim, T.R.; Rowe, R.C. Vegetative compatibility and virulence of strains of Verticillium dahliae from soil and potato plants. Phytopathology 1991, 81, 552-558. [CrossRef]

38. Milgroom, M.G.; Jimenez-Gasco, M.M.; Olivares, G.C.; Drott, M.T.; Jimenez-Diaz, R.M. Recombination between clonal lineages of the asexual fungus Verticillium dahliae detected by genotyping by sequencing. PLoS ONE 2014, 9, e106740. [CrossRef] [PubMed]

39. Amen, J.; Shoemaker, P.B. Histopathology of resistant and susceptible tomato cultivars inoculated with Verticillium dahliae races 1 and 2. Phytopathology 1985, 75, 1361-1362.

40. Vallad, G.E.; Qin, Q.M.; Grube, R.; Hayes, R.J.; Subbarao, K.V. Characterization of race-specific interactions among isolates of Verticillium dahliae pathogenic on lettuce. Phytopathology 2006, 96, 1380. [CrossRef] [PubMed]

41. Usami, T.; Momma, N.; Kikuchi, S.; Watanabe, H.; Hayashi, A.; Mizukawa, M.; Yoshino, K.; Ohmori, Y. Race 2 of Verticillium dahliae infecting tomato in japan can be split into two races with differential pathogenicity on resistant rootstocks. Plant Pathol. 2017, 66, 230-238. [CrossRef]

42. Schnathorst, W.C.; Mathre, D.E. Host range and differentiation of a severe form of Verticillium albo-atrum in cotton. Phytopathology 1966, 56, 1155-1161.

43. Klosterman, S.J.; Subbarao, K.V.; Kang, S.; Veronese, P.; Gold, S.E.; Thomma, B.P.; Chen, Z.; Henrissat, B.; Lee, H.; Park, J.; et al. Comparative genomics yields insights into niche adaptation of plant vascular wilt pathogens. PLoS Pathog. 2011, 7, e1002137. [CrossRef]

44. $\quad$ de Jonge, R.; Bolton, M.D.; Kombrink, A.; van den Berg, G.C.M.; Yadeta, K.A.; Thomma, B.P. Extensive chromosomal reshuffling drives evolution of virulence in an asexual pathogen. Genome Res. 2013, 23, 1271-1282. [CrossRef] [PubMed]

45. Chen, D.; Wu, C.; Hao, C.; Huang, P.; Liu, H.; Bian, Z.; Xu, J.R. Sexual specific functions of Tub1 beta-tubulins require stage-specific RNA processing and expression in Fusarium graminearum. Environ. Microbiol. 2018, 20, 4009-4021. [CrossRef] [PubMed]

46. Inderbitzin, P.; Bostock, R.M.; Davis, R.M.; Usami, T.; Platt, H.W.; Subbarao, K.V. Phylogenetics and taxonomy of the fungal vascular wilt pathogen Verticillium, with the descriptions of five new species. PLoS ONE 2011, 6, e28341. [CrossRef]

47. de Jonge, R.; Esse, H.P.V.; Maruthachalam, K.; Bolton, M.D.; Santhanam, P.; Saber, M.K.; Zhang, Z.; Usami, T.; Lievens, B.; Subbarao, K.V.; et al. Tomato immune receptor Ve1 recognizes effector of multiple fungal pathogens uncovered by genome and RNA sequencing. Proc. Natl. Acad. Sci. USA 2012, 109, 5110-5115. [CrossRef]

48. Pérez-Artés, E.; García-Pedrajas, M.D.; Bejarano-Alcázar, J.; Jiménez-Díaz, R.M. Differentiation of cotton-defoliating and nondefoliating pathotypes of Verticillium dahliae by RAPD and specific PCR analyses. Eur. J. Plant Pathol. 2000, 106, 507-517. [CrossRef]

49. Pegg, G.F.; Brady, B.L. Verticillium Wilts; CABI: Wallingford, UK, 2001.

50. Isaac, I. A comparative study of pathogenic isolates of Verticillium. Trans. Br. Mycol. Soc. 1949, 32, 137-157. [CrossRef]

51. Malca, I.; Erwin, D.C.; Moje, W.; Jones, B. Effects of $\mathrm{pH}$ and carbon and nitrogen sources on the growth of Verticillium albo-atrum. Phytopathology 1966, 56, 401-406.

52. Cooper, R.M.; Wood, R.K.S. Regulation of synthesis of cell-wall degrading enzymes by Verticillium albo-atrum and Fusarium oxysporum f.sp lycopersici. Physiol. Plant Pathol. 1975, 5, 135-156. [CrossRef]

53. Jing, R.; Li, H.; Hu, X.; Shang, W.; Shen, R.; Guo, C.; Guo, Q.; Subbarao, K.V. Verticillium wilt caused by V. dahliae and V. nonalfalfae in potato. Plant Dis. 2018, 102, 1958-1964. [CrossRef] [PubMed]

54. Devaux, A.L.; Sackston, W.B. Taxonomy of Verticillium species causing wilt of horticultural crops in Quebec. Can. J. Bot. Rev. Can. Bot. 1966, 44, 803-811. [CrossRef]

55. Brinkerhoff, L.A. The influence of temperature, aeration, and soil microflora on microsclerotial development of Verticillium albo-atrum in abscised cotton leaves. Phytopathology 1969, 59, 805-808.

56. Wang, Y.; Hu, X.; Fang, Y.; Anchieta, A.; Goldman, P.H.; Hernandez, G.; Klosterman, S.J. Transcription factor VdCmr1 is required for pigment production, protection from UV irradiation, and regulates expression of melanin biosynthetic genes in Verticillium dahliae. Microbiology 2018, 164, 685-696. [CrossRef]

57. Pethybridge, G.H. The Verticillium disease of the potato. Sci. Proc. R. Dublin Soc. 1916, 15, 63-92.

58. Caroselli, N.E.; Mahadevan, A.; Mozumder, B.G. The effect of light quality on the growth and microsclerotial production of Verticillium albo-atrum. Plant Dis. Rep. 1964, 48, 484-486.

59. Kaiser, W.J. Influences of light on the production of microsclerotia by Verticillium albo-atrum. Phytopathology 1962, 52, 362.

60. Kaiser, W.J. Effects of light on growth and sporulation of the Verticillium wilt fungus. Phytopathology 1964, 54, 765-770.

61. Duressa, D.; Anchieta, A.; Chen, D.; Klimes, A.; Garcia-Pedrajas, M.D.; Dobinson, K.F.; Klosterman, S.J. RNA-seq analyses of gene expression in the microsclerotia of Verticillium dahliae. BMC Genom. 2013, 14, 607. [CrossRef] [PubMed]

62. Xiong, D.; Wang, Y.; Ma, J.; Klosterman, S.J.; Xiao, S.; Tian, C. Deep mRNA sequencing reveals stage-specific transcriptome alterations during microsclerotia development in the smoke tree vascular wilt pathogen, Verticillium dahliae. BMC Genom. 2014, 15, 324. [CrossRef] [PubMed] 
63. Jiménez-Díaz, R.M.; Millar, R.L. Sporulation on infected tissues, and presence of airborne Verticillium albo-atrum in alfalfa fields in New York. Plant Pathol. 1988, 37, 64-70. [CrossRef]

64. Zhang, L.; Ni, H.; Du, X.; Wang, S.; Ma, X.W.; Nürnberger, T.; Guo, H.S.; Hua, C. The Verticillium-specific protein VdSCP7 localizes to the plant nucleus and modulates immunity to fungal infections. New Phytol. 2017, 215, 368-381. [CrossRef] [PubMed]

65. Fromm, J. Xylem Development in Trees: From Cambial Divisions to Mature Wood Cells; Springer: Berlin/Heidelberg, Germany, 2013; Volume 20, pp. 3-39.

66. Zhang, D.D.; Wang, X.Y.; Chen, J.Y.; Kong, Z.Q.; Gui, Y.J.; Li, N.Y.; Bao, Y.M.; Dai, X.F. Identification and characterization of a pathogenicity-related gene VdCYP1 from Verticillium dahliae. Sci. Rep. 2016, 6, 27979. [CrossRef]

67. Herth, W. Calcofluor white and Congo red inhibit chitin microfibril assembly of Poterioochromonas evidence for a gap between polymerization and microfibril formation. J. Cell Biol. 1980, 87, 442-450. [CrossRef] [PubMed]

68. Wood, P.J. Specificity in the interaction of direct dyes with polysaccharides. Carbohydr. Res. 1980, 81, 271-287. [CrossRef]

69. Vaknin, Y.; Shadkchan, Y.; Levdansky, E.; Morozov, M.; Romano, J.; Osherov, N. The three Aspergillus fumigatus CFEM-domain GPI-anchored protein (CfmA-C) affect cell-wall stability but do not play a role in fungal virulence. Fungal Genet. Biol. 2014, 63, 55-64. [CrossRef]

70. Giaever, G.; Chu, A.M.; Li, N.; Connelly, C.; Johnston, M. Functional profiling of the Saccharomyces cerevisiae genome. Nature 2002, 418, 387-391. [CrossRef]

71. Sabnam, N.; Barman, S. WISH, a novel CFEM GPCR is indispensable for surface sensing, asexual and pathogenic differentiation in rice blast fungus. Fungal Genet. Biol. 2017, 105, 37-51. [CrossRef]

72. Liu, S.Y.; Chen, J.Y.; Wang, J.L.; Li, L.; Xiao, H.L.; Adam, S.M.; Dai, X.F. Molecular characterization and functional analysis of a specific secreted protein from highly virulent defoliating Verticillium dahliae. Gene 2013, 529, 307-316. [CrossRef]

73. Hu, X.P.; Gurung, S.; Short, D.P.G.; Sandoya, G.V.; Shang, W.J.; Hayes, R.J.; Davis, R.M.; Subbarao, K.V. Nondefoliating and defoliating strains from cotton correlate with races 1 and 2 of Verticillium dahliae. Plant Dis. 2015, 99, 1713-1720. [CrossRef]

74. Usami, T.; Itoh, M.; Amemiya, Y. Asexual fungus Verticillium dahliae is potentially heterothallic. J. Gen. Plant Pathol. 2009, 75, 422-427. [CrossRef]

75. Xiao, C.L.; Subbarao, K.V.; Schulbach, K.F.; Koike, S.T. Effects of crop rotation and irrigation on Verticillium dahliae microsclerotia in soil and wilt in cauliflower. Phytopathology 1998, 88, 1046. [CrossRef] [PubMed]

76. Alkher, H.; Hadrami, A.E.; Rashid, K.Y.; Adam, L.R.; Daayf, F. Cross-pathogenicity of Verticillium dahliae between potato and sunflower. Eur. J. Plant Pathol. 2009, 124, 505-519. [CrossRef] 